\section{Research Square \\ Preprints are preliminary reports that have not undergone peer review. \\ They should not be considered conclusive, used to inform clinical practice, or referenced by the media as validated information.}

\title{
Can Nutrition Education Improve the Nutrition Behavior and Anthropometric Indexes among Patients with Hypertension based on the Health Promotion Model?
}

\author{
Kamal Mirkarimi ( $\nabla$ ak.mirkarimi@gmail.com ) \\ Golestan University of Medical Sciences \\ Abdurrahman Charkazi \\ Golestan University of Medical Sciences \\ Alireza Heidari \\ Golestan University of Medical Sciences \\ Rahman Berdi Ozouni- Davaji \\ Golestan University of Medical Sciences
}

\section{Research Article}

Keywords: Anthropometry, Diet Records, Hypertension, Health Promotion, Obesity

Posted Date: January 25th, 2021

DOI: https://doi.org/10.21203/rs.3.rs-144840/v1

License: () (1) This work is licensed under a Creative Commons Attribution 4.0 International License. Read Full License 


\section{Abstract}

Background: Following the rapid urbanization, unhealthy diet, enhanced life expectancy, and sedentary lifestyle has led to an increase in the prevalence of CVD and its risk factors, such as hypertension. Self-care is introduced as "behaviors directed toward oneself or the environment to formulate one's functioning in the interest of one's life, and well-being. Can nutrition education improve the nutrition behavior and anthropometric indexes among patients with hypertension based on the Health Promotion Model?

Methods: A quasi-experimental and single-blind study was conducted on patients with hypertension attended to the Health Houses of Gorgan city of Iran between June 2018 and February 2019. To collect information, 68 patients in the control and 68 ones in the intervention arm were investigated. Data were collected by distributing self-administered questionnaires about HPM constructs, and testing 3-day diet record. Education was just conducted in the intervention arm including six sessions during three weeks, and in final, measurement was run two and six months after intervention.

Results: There was no difference between the two groups about constructs of the HPM, anthropometric indexes, systolic and diastolic blood pressure and nutritional behavior before education, while after education all variables were significantly changed in two and six months' follow-ups.

Conclusion: HPM-based education might be likely useful to improve nutritional behaviors in patients with hypertension and it can also be applied in the health system of Golestan Province.

\section{Introduction}

Cardiovascular disease (CVD) results in 17 million deaths per annum, nearly one-third of all deaths in global (1). Hypertension is a largely preventable risk factor for death and disability for CVD worldwide that can be controlled and treated $(2,3)$. The prevalence of hypertension is globally projected to augment from $26 \%$ in 2000 to $29.2 \%$ by 2025 (1) Annual premature death of 7.7 million and $6 \%$ of burden of disease (GBD) is universally attributable to hypertension (4). Given the numerous studies conducted in Iran, the prevalence of hypertension reported $25-35 \%$ in general (5), which is reported as the first cause of mortality in Iran (6). It is widely associated with chronic complications, including CVD and strokes (7).

Following the rapid urbanization, unhealthy diet, enhanced life expectancy, and sedentary lifestyle has led to an increase in the prevalence of CVD and its risk factors, such as hypertension (8).

Body Mass Index (BMI) has widely documented to be one the most leading risk factor of several specific causes, including CVD (9). In global, prevalence of obesity and obesity-associated diseases, particularly hypertension, have been increasing. The mean of BMl increased by $0.4-0.5 \mathrm{~kg} / \mathrm{m} 2 \mathrm{per}$ decade in men and women during 1980 and 2008 years across the world (10). According to the several studies, a high BMI is known as an independent risk factor for morbidity and mortality from CVD and some cancers in the population (11). Obesity is also a leading risk factor for many chronic diseases and can result in metabolic, orthopedic and cardiovascular diseases, as well as cancer (12).

Self-care is introduced as "behaviors directed toward oneself or the environment to formulate one's functioning in the interest of one's life, and well-being (13). Opinions and judgments of people play key roles to implement self-care behaviors (14). It is well documented that opinions and believe are essential in an emergence of behavior and also unhealthy behaviors considered as the major cause of hypertension. Perceptions are among the main predictors of behavior (15).

The Health Promotion Model was considered as a framework which was first proposed by Pander. Pender describes this model as a guide for understanding complex psychological processes, that motivate persons to modify their manner, and helps them to promote health and hygiene (16). Moreover, this model considers other important factors on the behavior, including interpersonal relation and situational effects as well as individuals' previous experiences (17). There are several problems in the establishment and maintenance of self-care behaviors and its complication, and hence it is necessary to apply behavior changing models and theories. One of these effective models and theories in healthy nutritional behavior are Health Promotion Model (18). Pender's health promotion model, consists of constructs including individual characteristics and experiences; behavior-specific cognitions (perceived benefits and barriers of action, perceived self-efficacy, situational influences and social support); and adherence to specific plans of action (19). Numerous studies well documented that HPM model could be beneficial as a theoretical framework to find major determinants of adherence to the chronic conditions such as hypertension (20), prediction of self-care adherence in patients undergoing coronary angioplasty (21), and prediction of nutritional behavior among diabetic patients (22).

The aim of this study was therefore, to examine the effectiveness of nutrition education on anthropometric indexes and dietary commitment among patients with hypertension based on the Health Promotion Model.

\section{Materials And Methods}

\subsection{Study design}

A quasi-experimental (pretest- posttest with a control group) study was conducted on patients with hypertension attended to the Health Houses that regularly provided by the routine cares.

\subsection{Participants}


The current study was conducted in Gorgan city of Iran between June 2018 and February 2019. The study protocol was approved by the Ethics Committee of Golestan University of Medical Sciences. Patients suitable for inclusion were as follows; a definitive diagnosis by a physician, having a health record in the Health House, lack of chronic and severe complications, no other lasting diseases, aged between 30 to 65 years, no history of surgery or hospitalization in the last three months, willingness to participate in the study, lack of specific mental illnesses and no dementia, and those excluded if they did not meet the following criteria; pregnancy during the study, need a special diet, involved with diseases and absent more than two sessions in the educational interventions. Prior to the study, the informed written consent was obtained by all patients.

To collect data, a standard 12- part questionnaire was used including, 1) demographic characteristics (job, education and marital status and ...), 2) nutritional knowledge (10 items, correct answers scored 2 and false, and I don't know scored 0, ranged 0 to 20) ,3) perceived benefits (nine items), 4) perceived barriers (10 items), 5) perceived self-efficacy (10 items), 6) affects related to behavior (eight items), 7) interpersonal influences (nine items), 8) situational influences (seven items), 9) commitment to action (nine items), 10) nutritional behavior, 11) nutritional follow-up (five items). Part 3 and 4 were 4 -point Likert scale and scored completely agree 4 , agree 3 , disagree 2 , and completely disagree 1 . Furthermore, parts of 6, 7, 8, 9 and 11 were 5-point Likert Scale and scored always 5 , often 4 , sometimes 3 , rarely 2 , never 1 . In final, self-efficacy was tested using a 10-point continuum such that patients with lower and higher self-efficacy select number of near 1 and 10, accordingly. This self-administered questionnaire was used and validated by Kamran et al (23). According to a pilot study, reliability of the questionnaire was as follows in detail; nutritional knowledge (0.81), perceived benefits (0.77), perceived barriers (0.84), perceived self-efficacy (0.75), affects related to behavior (0.82), interpersonal influences (0.91), situational influences (0.88), commitment to action (0.73).

\subsubsection{Outcomes}

The primary outcomes were nutritional behavior that measured by the HPM-based standard questionnaire and 3-day diet record. While, the secondary ones were anthropometric indexes that tested using waist circumference, body weight, height, and BMI variables as well as hypertension.

\subsubsection{Variable definition}

Hypertension was defined as systolic blood pressure (SBP) $\geq 140 \mathrm{mmHg}$, or diastolic blood pressure (DBP) $\geq 90 \mathrm{mmHg}(10)$. According to the WHO criterion, BMl categorized into $25 \geq$ BMl 30 for overweight and $\geq 30$ for obesity (24).

\subsection{Interventions}

The present study was run in four stages, including, 1) educational planning, 2) sampling, 3) intervention and 4) evaluation.

\subsubsection{Educational planning}

A cross-sectional study was conducted to determine the effect of Pender Health Promotion Model constructs in predicting nutritional behaviors in patients with hypertension. By exploring the data, path analysis identified the most important factors affecting nutritional behavior. In final, education content was provided according to the cross-sectional study and Dietary Approach to Stop Hypertension (DASH).

\subsubsection{Sampling}

Four Health Houses were recruited. Before intervention, data were collected by distributing questionnaires about model constructs, 3-day diet record and their anthropometric indices.

\subsubsection{Educational intervention}

Education was just conducted in the intervention arm, including six sessions during three weeks (two sessions per week, 30 to 45 minutes for each session, and 17 patients were participated in each session). A brief overview of hypertension, symptoms, and side effects of non-controlling illness was presented by a public health student at the Health House for 10 minutes. At the end of the training sessions, nutrition education pamphlets were distributed to all study participants. Participant in the control group was only received the routine education for patients who usually provided by the health care personnel working in the Health Houses.

\subsubsection{Evaluation}

All participants had two and six months' assessments by personnel who were not involved in supporting the interventions.

\subsection{Measurements}

To measure BP, the patients were not recently indulged in any activity similar exercise or eating that may likely affect the BP, also the patients were quietly rested in a comfortable chair for 3 to 5 minutes with the upper arm at heart levels were tested. Three measurements were done in succession, separated by at 
least one minute (25).

Waist circumference was measured in the mid-axillary line at the midpoint between the costal margin and the iliac crest. Body weight was assessed to the closest $100 \mathrm{~g}$. Height was estimated with a stadio-meter to the nearest one $\mathrm{mm}$, and then BMI was calculated as weight $(\mathrm{kg}) / \mathrm{height}(\mathrm{m} 2)(26)$.

Nutritional behavior was measured using 3-day diet record (two normal days and one day off) and were also coded and verified by registered dietitians. In brief, it was estimated based on the energies consumed by macro and micro-nutrients.

All measurements were performed at pre-intervention (baseline), two and six month follow-ups.

\subsection{Sample size}

The sample size was estimated based on the repeated measurements as follows; correction factor $(R=0.44)$ in accordance with 0.6 of pre-test observation number $(v=1)$ and pre-test observation number $(w=2)$, significance level of 0.05 , statistical power $80 \%$ and the standardized effect size of $0.2,124$ patients were estimated that with consideration of attrition risk, 136 patients (68 patients in the control arm and 68 patients in the intervention arm) were recruited.

\subsection{Implementation}

Cluster sampling method was used such that from 80 Health Houses in the Golestan Province, 10 percent of them selected based on the systematic random sampling. Four Health Houses for the control arm and four ones for the intervention arm were enrolled. In total, 17 patients were provided with education in each Health House (68 in the control and 68 in the intervention arm).

\subsection{Blinding}

A single-blind study was implemented such that participants were blinded after assignment to the intervention.

\subsection{Data analyses}

T-test was used for comparing the means of two independent groups. One-way ANOVA was performed to examine means before and after intervention. For two dependent groups paired t-test was used. Repeated Measures ANOVA was examined in independent groups to find differences between groups over time. To predict the patient's nutritional behavior based on the HPM model, Linear Regression model was also used. Data analyzed by the SPSS software for windows (version 18), moreover, nutritionist (N4) software (version 4) was used to test nutritional variables. A P-value of $<0.05$ was considered significant.

\subsection{Declarations}

Kamal Mirkarimi: Preparing the manuscript, Abdurrahman Charkazi: data analyses, Alireza Heidari: preparing the manuscript, Rahman Berdi Ozouni- Davaji: implementation the education and supporting the interventions

\subsubsection{Ethics approval and consent to participate}

All methods were implemented in accordance with relevant guidelines and regulations. Also, all experimental protocols were approved by the Golestan University of Medical Sciences. In final, informed consent was obtained from all subjects.

\subsection{Availability of data and materials}

Data of the study will be provided by the corresponding author of the study through the website of the journal or by a valid email.

\section{Results}

Most of the patients were female (70\% in the intervention, $75 \%$ in the control group), in overall. According to the educational status, $45 \%$ in the intervention and $37.5 \%$ in the control group were illiterate (table 1 ). 
Table 1

Characteristics of the patients in the intervention and control groups

\begin{tabular}{|c|c|c|c|c|c|c|}
\hline \multicolumn{2}{|l|}{ Variables } & \multicolumn{2}{|l|}{ Intervention } & \multicolumn{2}{|l|}{ Control } & \multirow[t]{2}{*}{ P-value } \\
\hline & & Frequency & Percent & Frequency & Percent & \\
\hline \multirow[t]{2}{*}{ Gender } & Male & 12 & 30 & 10 & 25 & \multirow[t]{2}{*}{0.11} \\
\hline & Female & 28 & 70 & 30 & 75 & \\
\hline \multirow[t]{4}{*}{ Education status } & Illiterate & 11 & 27.5 & 13 & 32.5 & \multirow[t]{4}{*}{0.25} \\
\hline & Under diploma & 18 & 45 & 15 & 37.5 & \\
\hline & Diploma & 7 & 17.5 & 9 & 22.5 & \\
\hline & Academic & 4 & 10 & 3 & 7.5 & \\
\hline \multirow[t]{2}{*}{ Family history } & Yes & 16 & 40 & 19 & 47.5 & \multirow[t]{2}{*}{0.19} \\
\hline & No & 24 & 60 & 21 & 52.5 & \\
\hline \multicolumn{2}{|l|}{ Variables } & Mean & *SD & Mean & *SD & P-value \\
\hline \multicolumn{2}{|l|}{ Age } & 46.2 & 4.3 & 45.7 & 5.1 & 0.18 \\
\hline \multicolumn{2}{|l|}{ Body Mass Index } & 28.6 & 5.4 & 28.1 & 6.6 & 0.12 \\
\hline \multicolumn{2}{|l|}{$\mathrm{SBP}(\mathrm{mm} \mathrm{Hg})$} & 141.2 & 11.5 & 140.8 & 11.3 & 0.18 \\
\hline \multicolumn{2}{|l|}{ DBP $(\mathrm{mm} \mathrm{Hg})$} & 88.3 & 5.5 & 87.9 & 4.7 & 0.26 \\
\hline \multicolumn{2}{|c|}{ Disease duration (year) } & 7.2 & 3.5 & 6.8 & 4.1 & 0.71 \\
\hline
\end{tabular}

There was no difference between the two groups about constructs of the HPM before education (baseline); while after providing education, all scores of the constructs were significantly increased in two and six months' follow-up $(p<0.001)$ (table 2$)$.

Table 2

The mean and comparison of the HPM constructs between the intervention and control groups at the baseline, 2 and 6 month follow-up

\begin{tabular}{|c|c|c|c|c|c|c|c|c|c|c|c|c|c|c|c|}
\hline \multirow[t]{3}{*}{ Constructs } & \multicolumn{4}{|c|}{ Baseline } & \multirow{3}{*}{$\begin{array}{l}\text { P } \\
\text { (Between } \\
\text { groups) }\end{array}$} & \multicolumn{4}{|c|}{$\begin{array}{l}2 \text { months } \\
\text { follow-up }\end{array}$} & \multirow{3}{*}{$\begin{array}{l}\text { P } \\
\text { (Between } \\
\text { groups) }\end{array}$} & \multicolumn{4}{|c|}{$\begin{array}{l}6 \text { months } \\
\text { follow- up }\end{array}$} & \multirow{3}{*}{$\begin{array}{l}\text { P } \\
\text { (Between } \\
\text { groups) }\end{array}$} \\
\hline & \multicolumn{2}{|c|}{ Intervention } & \multicolumn{2}{|c|}{ Control } & & \multicolumn{2}{|c|}{ Intervention } & \multicolumn{2}{|c|}{ Control } & & \multicolumn{2}{|c|}{ Intervention } & \multicolumn{2}{|c|}{ Control } & \\
\hline & Mean & SD & Mean & SD & & Mean & SD & Mean & SD & & Mean & SD & Mean & SD & \\
\hline Knowledge & 12.3 & 2.9 & 11.8 & 3.2 & 0.43 & 15.4 & 3.8 & 12.1 & 2.1 & $<0.001$ & 18.9 & 3.7 & 12.8 & 2.4 & $<0.001$ \\
\hline $\begin{array}{l}\text { Perceived } \\
\text { benefits }\end{array}$ & 26.5 & 3.2 & 26.1 & 3 & 0.61 & 32.9 & 3.2 & 26.6 & 2.5 & $<0.001$ & 34.3 & 4.2 & 27.2 & 2.1 & $<0.001$ \\
\hline $\begin{array}{l}\text { Perceived } \\
\text { barriers }\end{array}$ & 27.3 & 4.5 & 28.7 & 4.9 & 0.02 & 18.3 & 4.8 & 28 & 3.6 & $<0.001$ & 10.8 & 5.2 & 27.7 & 3.3 & $<0.001$ \\
\hline Self-efficacy & 30.7 & 15.8 & 31.6 & 16.5 & 0.67 & 34.4 & 17.8 & 31.1 & 18.2 & $<0.001$ & 37.8 & 19.2 & 30.2 & 19.9 & $<0.001$ \\
\hline $\begin{array}{l}\text { Affects } \\
\text { related to } \\
\text { behavior }\end{array}$ & 26.7 & 4.7 & 25.2 & 4.6 & 0.31 & 35.2 & 6.4 & 26.3 & 3.1 & $<0.001$ & 38.6 & 6.6 & 26.1 & 2.9 & $<0.001$ \\
\hline $\begin{array}{l}\text { Interpersonal } \\
\text { influences }\end{array}$ & 24.4 & 3.2 & 23.1 & 4.1 & 0.41 & 31.7 & 4.2 & 22.5 & 4 & $<0.001$ & 39.3 & 4.3 & 22.2 & 4.3 & $<0.001$ \\
\hline $\begin{array}{l}\text { Situational } \\
\text { influences }\end{array}$ & 25.7 & 5.2 & 26.1 & 4.9 & 0.67 & 30.6 & 4.2 & 25.4 & 3.5 & $<0.001$ & 33.7 & 4.4 & 25.4 & 3.1 & $<0.001$ \\
\hline $\begin{array}{l}\text { Commitment } \\
\text { to action }\end{array}$ & 31.9 & 5.3 & 30.21 & 5.8 & 0.41 & 40.5 & 6.65 & 29.7 & 7.65 & $<0.001$ & 42.8 & 7.02 & 29.1 & 7.17 & $<0.001$ \\
\hline \multicolumn{16}{|c|}{ SD: Standard Deviation } \\
\hline \multicolumn{16}{|l|}{ C: Control } \\
\hline I: Intervention & & & & & & & & & & & & & & & \\
\hline
\end{tabular}


Given table 3, all anthropometric indicators, including waist, weight and BMI were remarkably decreased 2 and 6 months after the education in the intervention group ( $p$ <.001). Moreover, a statistical significant difference was found between the two groups in terms of SBP and DBP 2 and 6 months after intervention $(p<0.001)$.

Table 3

The anthropometric and blood pressure status between the intervention and control groups at the baseline, 2 and 6 month follow-up

\begin{tabular}{|c|c|c|c|c|c|c|c|c|c|c|c|c|c|c|c|c|}
\hline \multirow[t]{3}{*}{ Constructs } & \multicolumn{4}{|c|}{ Baseline } & \multirow{3}{*}{$\begin{array}{l}\text { P } \\
\text { (Between } \\
\text { groups) }\end{array}$} & \multicolumn{4}{|c|}{$\begin{array}{l}2 \text { months } \\
\text { follow-up }\end{array}$} & \multirow{3}{*}{$\begin{array}{l}\text { P } \\
\text { (Between } \\
\text { groups) }\end{array}$} & \multicolumn{4}{|c|}{$\begin{array}{l}6 \text { months } \\
\text { follow- up }\end{array}$} & \multirow{3}{*}{$\begin{array}{l}\text { P } \\
\text { (Between } \\
\text { groups) }\end{array}$} & \multirow{3}{*}{$\begin{array}{l}\text { P } \\
\text { Wit } \\
\text { grol } \\
\text { C }\end{array}$} \\
\hline & \multicolumn{2}{|c|}{ Intervention } & \multicolumn{2}{|c|}{ Control } & & \multicolumn{2}{|c|}{ Intervention } & \multicolumn{2}{|c|}{ Control } & & \multicolumn{2}{|c|}{ Intervention } & \multicolumn{2}{|c|}{ Control } & & \\
\hline & Mean & SD & Mean & SD & & Mean & SD & Mean & SD & & Mean & SD & Mean & SD & & \\
\hline $\begin{array}{l}\text { Waist } \\
(\mathrm{cm})\end{array}$ & 107.2 & 12.4 & 108.5 & 12.8 & 0.78 & 104.3 & 3.2 & 107.8 & 3.4 & $<0.001$ & 99.8 & 3.9 & 107.3 & 3.7 & $<0.001$ & 0.17 \\
\hline $\begin{array}{l}\text { Weight } \\
(\mathrm{kg})\end{array}$ & 78.9 & 9.2 & 77.7 & 9.9 & 0.61 & 74.1 & 1.9 & 77.2 & 2.3 & $<0.001$ & 71.1 & 2 & 76.6 & 2.5 & $<0.001$ & 0.85 \\
\hline $\begin{array}{l}\text { BMl } \\
\left(\mathrm{kg} / \mathrm{m}^{2}\right)\end{array}$ & 31.1 & 5.2 & 29.9 & 4.8 & 0.33 & 30.8 & 0.43 & 29.8 & 0.57 & $<0.001$ & 29.2 & 1.1 & 29.8 & 1.3 & $<0.001$ & 0.31 \\
\hline $\begin{array}{l}\text { Systolic } \\
\text { blood } \\
\text { pressure } \\
(\mathrm{mmHg})\end{array}$ & 144.2 & 8.8 & 145.4 & 7.9 & 0.57 & 140.1 & 6.7 & 145.2 & 7.4 & $<0.001$ & 135.2 & 9.4 & 145 & 11.6 & $<0.001$ & $0.5 \mathrm{c}$ \\
\hline $\begin{array}{l}\text { Diastolic } \\
\text { blood } \\
\text { pressure } \\
(\mathrm{mmHg})\end{array}$ & 87.3 & 4.2 & 89.4 & 5.4 & 0.42 & 80.4 & 3.7 & 89.1 & 6.1 & $<0.001$ & 76.2 & 4.7 & 89.1 & 6.9 & $<0.001$ & 0.63 \\
\hline
\end{tabular}

SD: Standard Deviation

C: Control

I: Intervention

Macro-nutrients usage and their energy intakes were significantly different between the two groups in two and six months' follow-up ( $p<0.001)$, such that fat consumption was decreased, while carbohydrates and protein consumption were increased in the intervention group at two and six months' follow-up (table 4). 
Table 4

The mean and comparison of Macro and Micronutrients and their energies between the intervention and control groups at the baseline, 2 and 6

\begin{tabular}{|c|c|c|c|c|c|c|c|c|c|c|c|c|c|c|}
\hline \multirow{3}{*}{$\begin{array}{l}\text { Constructs } \\
\text { Mean }\end{array}$} & \multicolumn{4}{|c|}{ Baseline } & \multirow{3}{*}{$\begin{array}{l}\text { P } \\
\text { (Between } \\
\text { groups) } \\
\text { SD }\end{array}$} & \multicolumn{4}{|c|}{$\begin{array}{l}2 \text { months } \\
\text { follow-up }\end{array}$} & \multirow{3}{*}{$\begin{array}{l}\text { P } \\
\text { (Between } \\
\text { groups) } \\
\text { Mean }\end{array}$} & \multirow{2}{*}{\multicolumn{2}{|c|}{$\begin{array}{l}6 \text { months } \\
\text { follow- up } \\
\text { Intervention }\end{array}$}} & \multirow{3}{*}{$\begin{array}{l}\text { Control } \\
\text { I }\end{array}$} & \\
\hline & \multicolumn{2}{|c|}{ Intervention } & \multicolumn{2}{|l|}{ Control } & & \multicolumn{2}{|c|}{ Intervention } & \multicolumn{2}{|l|}{ Control } & & & & & \\
\hline & SD & Mean & SD & Mean & & Mean & SD & Mean & SD & & SD & C & & \\
\hline Fat (gr) & 89.7 & 26.7 & 81.6 & 20.4 & 0.21 & 75.5 & 24.5 & 81.4 & 25.4 & $<0.001$ & 68.7 & 28.2 & 80.8 & 27.4 \\
\hline $\begin{array}{l}\text { Energy from } \\
\text { fat (Kcal) }\end{array}$ & 32.2 & 3.5 & 31.8 & 3.1 & 0.69 & 25.7 & 4.7 & 31.6 & 3.8 & $<0.001$ & 20.3 & 4.4 & 30.6 & 4.1 \\
\hline $\begin{array}{l}\text { Carbohydrate } \\
\text { (gr) }\end{array}$ & 341.4 & 45.7 & 358.1 & 49.3 & 0.65 & 352.1 & 58.1 & 357.3 & 55.6 & $<0.001$ & 355.3 & 62.9 & 358.3 & 65.4 \\
\hline $\begin{array}{l}\text { Energy from } \\
\text { carbohydrate } \\
\text { (Kcal) }\end{array}$ & 52.5 & 4.8 & 51.3 & 5.2 & 0.41 & 72.5 & 5.9 & 51.1 & 5.7 & $<0.001$ & 74 & 6 & 51.2 & 6.1 \\
\hline Protein (gr) & 121.5 & 32.1 & 118.6 & 28.6 & 0.24 & 132.2 & 21.7 & 118.2 & 24.5 & $<0.001$ & 134.8 & 23.2 & 117.7 & 26.1 \\
\hline $\begin{array}{l}\text { Energy from } \\
\text { protein (Kcal) }\end{array}$ & 21.2 & 3.2 & 20.7 & 3 & 0.18 & 20.4 & 3.1 & 20.5 & 2.6 & $<0.001$ & 21.5 & 3.2 & 19.8 & 3.5 \\
\hline Sodium (mg) & 2766.1 & 437.6 & 2775 & 487.2 & 0.87 & 2107 & 357.5 & 2713 & 456.1 & $<0.001$ & 1978 & 346.3 & 2763 & 437.2 \\
\hline $\begin{array}{l}\text { Calcium } \\
\text { (mg) }\end{array}$ & 752.1 & 431.5 & 723.5 & 375.8 & 0.43 & 451.4 & 454.9 & 715.8 & 348.7 & $<0.001$ & 368.5 & 312.8 & 723.8 & 312.5 \\
\hline $\begin{array}{l}\text { Potassium } \\
\text { (mg) }\end{array}$ & 3321.7 & 657.3 & 3254.1 & 612.5 & 0.32 & 1769.3 & 756.2 & 3187.6 & 548.5 & $<0.001$ & 1532.4 & 698.2 & 3183.2 & 598.2 \\
\hline \multicolumn{15}{|c|}{ SD: Standard Deviation } \\
\hline \multicolumn{15}{|l|}{ C: Control } \\
\hline
\end{tabular}

Table 5 indicates that all the constructs of the HPM predicted the patient's nutritional behavior when they were entered in the model separately. While, after adjustment, four of them, namely perceived benefits $(P=0.001)$, nutritional knowledge $(P=0.001)$, perceived self-efficacy $(P=0.023)$, and affects related to the behavior ( $\mathrm{P}=0.001)$, were able to significantly predict the patient's nutritional behavior.

Table 5

Predicting nutritional behavior based on the constructs using adjusted and unadjusted regression model

\begin{tabular}{|lllll|}
\hline \multirow{2}{*}{ Constructs } & \multicolumn{2}{l}{ Unadjusted } & \multicolumn{2}{l|}{ Adjusted } \\
\cline { 2 - 5 } & $\boldsymbol{\beta}$ & P-value & $\boldsymbol{\beta}$ & P-value \\
\hline Nutritional knowledge & 0.28 & 0.001 & 0.257 & 0.001 \\
\hline Perceived benefits & 0.42 & 0.001 & 0.528 & 0.001 \\
\hline Perceived barriers & -0.31 & 0.001 & 0.033 & 0.451 \\
\hline Perceived self-efficacy & 0.25 & 0.037 & 0.218 & 0.023 \\
\hline Affects related to the behavior & 0.43 & 0.001 & 0.132 & 0.001 \\
\hline Interpersonal influences & 0.18 & 0.001 & 0.021 & 0.167 \\
\hline Situational influences & 0.32 & 0.001 & 0.034 & 0.231 \\
\hline Commitment to action & 0.15 & 0.021 & 0.073 & 0.102 \\
\hline
\end{tabular}

ANOVA repeated measure illustrated that score of the constructs, anthropometric indexes, SBP and DBP as well as macro and micro-nutrients intakes were significantly changed two and six months after intervention $(P=0.001)$ (all tables).

\section{Discussion}

\subsection{Knowledge}


Knowledge plays a key role in commitment to dietary among patients with hypertension (27) such that numerous studies mentioned lack of knowledge as a problem to control hypertension $(28,29)$. In a study conducted by Spencer et al, poor dietary knowledge introduced as a barrier for controlling diet in DASH approach(30). At present, patients were moderately provided by the knowledge that was in associated with other studies (30, 31). In relevance to present, several studies implemented in the rural area reported poor knowledge toward dietary $(32,33)$, also investigations in the urban area indicated the same results $(34,35)$.

\subsection{Benefits and barriers}

Patients range moderate to high in the benefits and barrier's scores, currently. Two aforementioned constructs describe the action of individuals by balancing or unbalancing the perceived positive and negative forces on health behavior (18). Perceived barriers in Kamran et al study were difficulties in preparing lowsalt foods, deprivation of tastes of some foods, being tired of having a diet, and being deprived of party and high cost of diet foods (23).

\subsection{Self-efficacy}

Bandura views self-efficacy as the strongest predictor of behavior change in the individual, and those with the most behavior change usually have a higher level of self-efficacy for specific behaviors (36). Presently, self-efficacy scores of patients were in a poor range, nearly. Our findings were not similar to Pariad et al study that investigated the patients with cardiovascular disease (37). In addition, Waren et al found good self-efficacy for patients with hypertension, although they studied self-efficacy for weight loss (38). The majority of our patients were female villagers with low literacy that might be the reason of their low self-efficacy, since factors such as age, gender, education level and area of residence as well as access to health services can affect self-efficacy (37).

\subsection{Interpersonal influences}

Social influence and the effects of others, including family members have been identified as both a facilitator and a deterrent to blood pressure control (39). Family members play a vital role in the self-care, including help to select and preparation of food (40), assisting in the perception and adherence to nutritional recommendations (39), facilitating communication between the patient and care providers and talking about hypertensive care (41) and encouraging behavior change (39). Presently, the score of the construct was improved that might be likely due to family support, especially a spouse for adhering to the diet.

\subsection{Situational influences}

This construct importantly affects on diet commitment. Horowits et al found that it is impossible to follow the nutritional recommendations provided in the community in which they live, because their environmental and cultural conditions were unsuitable for their application (42). In a study done by Guardia et al, environmental conditions had a significant effect on behavioral intention to reduce sodium in meat products and acceptance of low sodium sausages (43). In brief, nutritional behavior is influenced by individual, psychological, and social factors that are important for understanding and establishing the necessary contexts for behavior change.

\subsection{Affects related to behavior}

Feelings act as a driving force for people to take decisions and think (44). 0, Reily et al indicated the association of feelings with obesity (45). In the Morowatti et al study, reluctance was the most important barrier to self-care behaviors, and then over-exertion was of secondary importance (46). At present, score of the construct was improved after education in the intervention group. This increase means that people have more positive emotions than healthy eating, which increases the likelihood of dietary recommendations because positive emotions have a significant relationship with nutrition (45).

\subsection{Commitment to action}

After education, significant differences were found in the intervention group during the times of the study. Scholars believe that techniques such as problemsolving and behavioral commitment can result in behavior change and finally can lead to positive results (47). Given HPM, commitment to a behavior is less likely to lead to desirable behavior if there are other attractive behaviors. Thus, programmed approach focusing on barriers and perceived self-efficacy as well as other constructs of the HPM with direct and indirect relation with the commitment to action can finally result in the planned behaviors (48).

\subsection{Nutritional follow-up}

Adherence to dietary advice is a vital component in preventing the onset and progression of many chronic dietary disorders (49). According to the several studies, there is a significant relationship between adherence to the DASH approach and SBP and DBP, such that a higher score on adherence to the recommended approach reduces blood pressure further $(50,51)$. In Encore et al study, adherence to the DASH diet was an independent predictor of SBP (50). Although, score of the constructs was improved in the intervention group, presently, but it is widely documented that score of adherence to the approach was low $(50,52)$. In a review article conducted by Desrocheset al, the results of 123 nutritional education interventions for the prevention and control of chronic diseases were evaluated, and only 32 studies reported favorable changes in diet adherence(53). Transform knowledge into action (54), pay attention to the patient-centric process in consultations (55), increase patient motivation to follow the recommendations (50) can help to keep to the diet. 


\subsection{SBP and DBP}

Hypertension is a result of genetics and environmental factors that nutrition is the most important one. Nutritional intervention can be considered as the first step before initiating drug therapy and in people taking the medication adherence can help to decrease BP (56). Currently, SBP and DBP were remarkably decreased in the intervention group at all follow- ups. A number of studies have indicated a positive effect of the DASH approach to decrease hypertension $(57,58)$. Of course, the DASH approach has not always been beneficial $(59,60)$. At present, the success of DASH approach can be likely due to the theoretical framework used in this intervention, commitment to behavior, training to improve behavioral perceptions and optimal dietary follow-up.

\subsection{Anthropometric indexes}

The current results reported significant differences during follow-ups in the intervention group that also indicated by other scholars such that DASH approach could decrease the obesity (61). In a controversial result, Aucott et al found that although weight loss was maintained, but SBP increased and returned to the pre-intervention stage. In the aforementioned review study, BMI and waist were significantly decreased two and six months after intervention (62). Positive effect of weight loss on blood pressure control is recommended (38). Extensive communication, rational goals, continuous monitoring is effective weight loss strategies. Furthermore, nutrition and lifestyle changes are the forefront of a weight loss strategy (63).

\subsection{Macro and micro-nutrients}

As the DASH approach expects, at present, fat and protein consumption was decreased while carbohydrate usage was increased. In association with our study, other ones delineated that DASH approach-based interventions resulted in decrease in fat consumption (52, 64). The DASH approach emphasizes the consumption of high-carbohydrate diets (complex carbohydrates) including grains, vegetables and dietary fiber (65). In some studies investigating the relationship between carbohydrate intake and blood pressure, conflicting results have been found including, direct association and inverse association (66) and in others not significant (56). Protein intake was also decreased in the intervention group that was in accordance with other studies(67, 68). Although, incompatible results were found, as well (69). The type of protein consumed (animal, plant) may have different effects on blood pressure (69). According to the DASH approach, reduce sodium intake and increased intake of potassium, calcium and magnesium can decrease hypertension (70). It is recommended to limit salt intake in patients with hypertension and abnormal blood pressure of 5 to 6 grams per day, which may be effective in lowering blood pressure (71) that partly achieved in the current intervention group. DASH approach, especially emphasizes on consumption of low-fat dairy products that achieved in the intervention group. Potassium intake in most countries is below the recommended level (72). The recommended potassium level in the DASH approach is $4700 \mathrm{mg}$ (73), which despite the significant increase, did not reach the recommended target for the intervention group.

\section{Conclusions}

Hypertension is widely increasing among the Iranian population in the rural and urban area due to civilization and sedentary lifestyle. According to the Golestan health system statistics, hypertension has always been a major public health problem that imposes a huge burden on the health system despite all health care services. Therefore, the current findings might likely be beneficial as a theoretical education framework by replacing the new educations by the old and affect less ones.

\section{Strength And Limitation Of The Study}

The present study as a framework-based study implemented to identify factors of hypertension that rarely done among housewife Iranian society. Also, to better find the effectiveness of intervention, 2 and 6-month follow-ups were measured. However, the study was conducted only among women which limits its generalizability.

\section{Declarations}

\section{Funding}

The study protocol was financially supported by the Golestan University of Medical Sciences.

\section{Acknowledgement}

Authors wish to thank patients who participated in the study and also Golestan University of Medical Sciences for its financial supports.

\section{Conflict of interest}

There was no conflict of interest

\section{Consent for publication}

All researchers are satisfied with the publication of the article in the BMC Public Health Journal. 


\section{References}

1. Rahman M, Zaman MM, Islam JY, Chowdhury J, Ahsan HN, Rahman R, et al. Prevalence, treatment patterns, and risk factors of hypertension and prehypertension among Bangladeshi adults. J Hum Hypertens. 2018;32:334-48.

2. Khosravi A, Emamian MH, Shariati M, Hashemi H, Fotouhi A. The prevalence of pre-hypertension and hypertension in an Iranian urban population. High blood pressure \& cardiovascular prevention. 2014;21:127-35.

3. Lim SS, Vos T, Flaxman AD, Danaei G, Shibuya K, Adair-Rohani H, et al. A comparative risk assessment of burden of disease and injury attributable to 67 risk factors and risk factor clusters in 21 regions, 1990-2010: a systematic analysis for the Global Burden of Disease Study 2010. The lancet. 2012;380:2224-60.

4. Forouzanfar MH, Liu P, Roth GA, Ng M, Biryukov S, Marczak L, et al. Global burden of hypertension and systolic blood pressure of at least 110 to 115 mm Hg, 1990-2015. Jama. 2017;317:165-82.

5. Kamran A, Sharifirad G, Shafaeei Y, Azadbakht L. Sodium intake prediction with health promotion model constructs in rural hypertensive patients. Indian J Public Health. 2015;59:102-8.

6. Sany SBT, Behzhad F, Ferns G, Peyman N. Communication skills training for physicians improves health literacy and medical outcomes among patients with hypertension: a randomized controlled trial. BMC Health Serv Res. 2020;20:10.

7. L Tuck M, B Corry D. Prevalence of obesity, hypertension, diabetes, and metabolic syndrome and its cardiovascular complications. Curr Hypertens Rev. 2010;6:73-82.

8. Joshi P, Islam S, Pais P, Reddy S, Dorairaj P, Kazmi K, et al. Risk factors for early myocardial infarction in South Asians compared with individuals in other countries. Jama. 2007;297:286-94.

9. Kjøllesdal MK, Smith GD, Ariansen I, Kinge JM, Degerud E, Næss $\emptyset$. The association between BMI and mortality using early adulthood BMI as an instrumental variable for midlife BMI. Sci Rep. 2018;8:1-9.

10. Silva DAS, Petroski EL, Peres MA. Accuracy and measures of association of anthropometric indexes of obesity to identify the presence of hypertension in adults: a population-based study in Southern Brazil. Eur J Nutr. 2013;52:237-46.

11. Xiong L, Cao S, Xu F, Zhou Q, Fan L, Xu Q, et al. Association of body mass index and body mass index change with mortality in incident peritoneal dialysis patients. Nutrients. 2015;7:8444-55.

12. Gröber-Grätz D, Widhalm K, De Zwaan M, Reinehr T, Blüher S, Schwab KO, et al. Body mass index or waist circumference: which is the better predictor for hypertension and dyslipidemia in overweight/obese children and adolescents? Association of cardiovascular risk related to body mass index or waist circumference. Horm Res Paediatr. 2013;80:170-8.

13. Salim H, Lee PY, Sazlina SG, Ching SM, Mawardi M, Shamsuddin NH, et al. The self-care profiles and its determinants among adults with hypertension in primary health care clinics in Selangor, Malaysia. PloS one. 2019;14:e0224649.

14. Peters RM, Templin TN. Theory of planned behavior, self-care motivation, and blood pressure self-care. Res Theory Nurs Pract. 2010;24:172-86.

15. Kamran A, Azadbakht L, Sharifirad G, Mahaki B, Mohebi S. The relationship between blood pressure and the structures of Pender's health promotion model in rural hypertensive patients. J Educ Health Promot. 2015;4:8.

16. Parsons MA, Pender NJ, Murdaugh CL. Health promotion in nursing practice: Pearson Higher Ed; 2011.

17. Kamran A, Azadbakht L, Sharifirad G, Mahaki B, Mohebi S. The relationship between blood pressure and the structures of Pender's health promotion model in rural hypertensive patients. J Educ Health Promot. 2015;4.

18. Mohebi S, Sharifirad G, Feizi A, Botlani S, Hozori M, Azadbakht L. Can health promotion model constructs predict nutritional behavior among diabetic patients? J Res Med Sci. 2013;18:346-59.

19. Shaahmadi F, Shojaeizadeh D, Sadeghi R, Arefi Z. Factors Influencing Health Promoting Behaviours in Women of Reproductive Age in Iran: Based on Pender's Health Promotion Model. Open Access Maced J Med Sci. 2019;7:2360-64.

20. Gorbani F, Mahmoodi H, Sarbakhsh P, Shaghaghi AJVH, Management R. Predictive performance of pender's health promotion model for hypertension control in iranian patients. 2020;16:299.

21. Khodaminasab A, Reisi M, Vahedparast $H$, Tahmasebi R, Javadzade HJPp, adherence. Utilizing a health-promotion model to predict self-care adherence in patients undergoing coronary angioplasty in Bushehr, Iran. 2019;13:409.

22. Mohebi S, Sharifirad G, Feizi A, Botlani S, Hozori M, Azadbakht LJJorimstojolUoMS. Can health promotion model constructs predict nutritional behavior among diabetic patients? 2013;18(4):346.

23. Kamran A, Sharifirad G, Azadbakht L. Assessing Nutritional Behaviors and Attitudes of Rural Hypertensive Patients Based on Pender Health Promotion Model. Ardabil University of Medical Sciences. 2013;3:85-98.

24. Mirkarimi K, Mostafavi F, BERDI ODR, Eshghinia S, Vakili MA. The effect of weight loss program on overweight and obese females based on protection motivation theory: A randomized control trial. Iran Red Crescent Med J. 2017;19:e29504.

25. Pickering TG, Hall JE, Appel LJ, Falkner BE, Graves J, Hill MN, et al. Recommendations for blood pressure measurement in humans and experimental animals: part 1: blood pressure measurement in humans: a statement for professionals from the Subcommittee of Professional and Public Education of the American Heart Association Council on High Blood Pressure Research. Hypertension. 2005;45:142-61.

26. Lopez-Legarrea P, Garcia-Rubio J, Oviedo-Silva F, Collado-Mateo D, Merellano-Navarro E, Olivares P. Waist circumference and waist: height ratio percentiles using LMS method in Chilean population. Nutr Metab Cardiovasc Dis. 2017;27:183-9. 
27. Ford CD, Kim MJ, Dancy BL. Perceptions of hypertension and contributing personal and environmental factors among rural Southern African American women. Ethnicity \& disease. 2009;19:407-13.

28. Baliz Erkoc S, Isikli B, Metintas S, Kalyoncu C. Hypertension Knowledge-Level Scale (HK-LS): a study on development, validity and reliability. Int J Environ Res Public Health. 2012;9:1018-29.

29. Oskay EM, Önsuz MF, Topuzoglu A. Assesment of hypertension knowledge, attitude and throught of policyclinic patients at a primary health care center in Izmir. Meandros Medical And Dental Journal. 2010;11:3-9.

30. Spencer A, Jablonski R, Loeb SJ. Hypertensive African American women and the DASH diet. Nurse Pract. 2012;37:41-6.

31. Sabouhi F, Babaee S, Naji H, Zadeh AH. Knowledge, awareness, attitudes and practice about hypertension in hypertensive patients referring to public health care centers in Khoor \& Biabanak. Iran J Nurs Midwifery Res. 2011;16:34-40.

32. Nkosi N, Wright S. Knowledge related to nutrition and hypertension management practices of adults in Ga-Rankuwa day clinics. Curationis. 2010;33:3340 .

33. Pandey RM, Agrawal A, Misra A, Vikram NK, Misra P, Dey S, et al. Population-based intervention for cardiovascular diseases related knowledge and behaviours in Asian Indian women. Indian heart journal. 2013;65:40-7.

34. Motlagh Z, Mazloomy S, Mozaffari Khosravi H, Morowatisharifabad M, Askarshahi M. Salt intake among women refer to medical health centers, Yazd, Iran, 2011. Journal of Shahid Sadoughi University of Medical Sciences. 2011;19:550-60.

35. Grimes CA, Riddell LJ, Nowson CA. Consumer knowledge and attitudes to salt intake and labelled salt information. Appetite. 2009;53:189-94.

36. Mularcik KA. Self-efficacy toward health behaviors to improve blood pressure in patients who receive care in a primary care network: The Ohio State University; 2010

37. Paryad E, Hosseinzade T, Kazemnejad E, Asiri S. A study of self-efficacy in patients with coronary artery disease and its predictors. Qom Univ Med Sci J. 2013;7:41-8.

38. Warren-Findlow J, Seymour RB, Huber LRB. The association between self-efficacy and hypertension self-care activities among African American adults. J Community Health. 2012;37:15-24.

39. Flynn SJ, Ameling JM, Hill-Briggs F, Wolff JL, Bone LR, Levine DM, et al. Facilitators and barriers to hypertension self-management in urban African Americans: perspectives of patients and family members. Patient Prefer Adherence. 2013;7:741.

40. Wilson DK, Ampey-Thornhill G. The role of gender and family support on dietary compliance in an African American adolescent hypertension prevention study. Ann Behav Med. 2001;23:59-67.

41. Wolff JL, Roter DL. Family presence in routine medical visits: a meta-analytical review. Social science \& medicine. 2011;72:823-31.

42. Horowitz CR, Tuzzio L, Rojas M, Monteith SA, Sisk JE. How do urban African Americans and Latinos view the influence of diet on hypertension? J Health Care Poor Underserved. 2004;15:631-44.

43. Roca B, Nadal E, Rovira RE, Valls S, Lapuebla C, Lloria N. Usefulness of a hypertension education program. Southern medical journal. 2003;96:1133-38.

44. Colchamiro R, Ghiringhelli K, Hause J. Touching hearts, touching minds: using emotion-based messaging to promote healthful behavior in the Massachusetts WIC program. J Nutr Educ Behav. 2010;42:S59-S65.

45. O'Reilly GA, Cook L, Spruijt-Metz D, Black DS. Mindfulness-based interventions for obesity-related eating behaviours: a literature review. Obes Rev. 2014;15:453-61.

46. Morowatisharifabad M, Rouhani Tonekaboni N. The relationship between perceived benefits/barriers of self-care behaviors and self management in diabetic patients. Journal of hayat. 2007;13:17-27.

47. Treatment CfSA. Enhancing motivation for change in substance abuse treatment1999.

48. Pender NJ, Murdaugh CL, Parsons MA. Health promotion in nursing practice2006.

49. Desroches S, Lapointe A, Ratté S, Gravel K, Légaré F, Thirsk J. Interventions to enhance adherence to dietary advice for preventing and managing chronic diseases in adults: a study protocol. BMC Public Health. 2011;11:111.

50. Epstein DE, Sherwood A, Smith PJ, Craighead L, Caccia C, Lin P-H, et al. Determinants and consequences of adherence to the dietary approaches to stop hypertension diet in African-American and white adults with high blood pressure: results from the ENCORE trial. J Acad Nutr Diet. 2012;112:1763-73.

51. Obarzanek E, Vollmer WM, Lin P-H, Cooper LS, Young DR, Ard JD, et al. Effects of individual components of multiple behavior changes: the PREMIER trial. Am J Health Behav. 2007;31:545-60.

52. Racine E, Troyer J, Warren-Findlow J, McAuley WJ. The effect of medical nutrition therapy on changes in dietary knowledge and DASH diet adherence in older adults with cardiovascular disease. The journal of nutrition, health \& aging. 2011;15:868-76.

53. Desroches S, Lapointe A, Ratte S, Gravel K, Legare F, Turcotte S. Interventions to enhance adherence to dietary advice for preventing and managing chronic diseases in adults. Cochrane Database Syst Rev. 2013.

54. Desroches S, Lapointe A, Ratté S, Gravel K, Légaré F, Thirsk J. Interventions to enhance adherence to dietary advice for preventing and managing chronic diseases in adults: a study protocol. BMC Public Health. 2011;11(1):111.

55. MacLellan DL, Berenbaum S. Dietitians' opinions and experiences of client-centred nutrition counselling. Can J Diet Pract Res. 2006;67:119-24.

56. Appel LJ, Brands MW, Daniels SR, Karanja N, Elmer PJ, Sacks FM. Dietary approaches to prevent and treat hypertension: a scientific statement from the American Heart Association. Hypertension. 2006;47:296-308.

57. Azadbakht L, Fard NRP, Karimi M, Baghaei MH, Surkan PJ, Rahimi M, et al. Effects of the Dietary Approaches to Stop Hypertension (DASH) eating plan on cardiovascular risks among type 2 diabetic patients: a randomized crossover clinical trial. Diabetes care. 2011;34:55-7.

Page $11 / 12$ 
58. Nowson CA, Worsley A, Margerison C, Jorna MK, Godfrey SJ, Booth A. Blood pressure change with weight loss is affected by diet type in men. Am J Clin Nutr. 2005;81:983-9.

59. Whitt-Glover MC, Hunter JC, Foy CG, Quandt SA, Vitolins MZ, Leng I, et al. Translating the Dietary Approaches to Stop Hypertension (DASH) diet for use in underresourced, urban African American communities, 2010. Prev Chronic Dis. 2013;10:120088-92.

60. Rankins J, Sampson W, Brown B, Jenkins-Salley T. Dietary Approaches to Stop Hypertension (DASH) intervention reduces blood pressure among hypertensive African American patients in a neighborhood health care center. J Nutr Educ Behav. 2005;37:259-64.

61. Hinderliter AL, Sherwood A, Craighead LW, Lin P-H, Watkins L, Babyak MA, et al. The long-term effects of lifestyle change on blood pressure: One-year follow-up of the ENCORE study. Am J Hypertens. 2014;27:734-41.

62. Aucott L, Rothnie H, McIntyre L, Thapa M, Waweru C, Gray D. Long-term weight loss from lifestyle intervention benefits blood pressure? A systematic review. Hypertension. 2009;54:756-62.

63. Bray G, Look M, Ryan D. Treatment of the obese patient in primary care: targeting and meeting goals and expectations. Postgraduate medicine. 2013;125:67-77.

64. Troyer JL, Racine EF, Ngugi GW, McAuley WJ. The effect of home-delivered Dietary Approach to Stop Hypertension (DASH) meals on the diets of older adults with cardiovascular disease. Am J Clin Nutr. 2010;91:1204-12.

65. Kwan MW-M, Wong MC-S, Wang HH-X, Liu KQ-L, Lee CL-S, Yan BP-Y, et al. Compliance with the Dietary Approaches to Stop Hypertension (DASH) diet: a systematic review. PLoS One. 2013;8:e78412.

66. Visvanathan R, Chen R, Horowitz M, Chapman I. Blood pressure responses in healthy older people to $50 \mathrm{~g}$ carbohydrate drinks with differing glycaemic effects. Br J Nutr. 2004;92:335-40.

67. Tiukinhoy S, Rochester CL. Effects of Protein, Monounsaturated Fat, and Carbohydrate Intake on Blood Pressure and Serum Lipids. J Cardiopulm Rehabil Prev. 2006;26:119.

68. Delbridge EA, Prendergast LA, Pritchard JE, Proietto J. One-year weight maintenance after significant weight loss in healthy overweight and obese subjects: does diet composition matter? Am J Clin Nutr. 2009;90:1203-14.

69. Altorf-van der Kuil W, Engberink MF, Vedder MM, Boer JM, Verschuren WM, Geleijnse JM. Sources of dietary protein in relation to blood pressure in a general Dutch population. PloS one. 2012;7:e30582.

70. Karppanen H, Karppanen P, Mervaala E. Why and how to implement sodium, potassium, calcium, and magnesium changes in food items and diets? $\mathrm{J}$ Hum Hypertens. 2005;19:10-9.

71. He FJ, Burnier M, MacGregor GA. Nutrition in cardiovascular disease: salt in hypertension and heart failure. Eur Heart J. 2011;32:3073-80.

72. Nguyen H, Odelola OA, Rangaswami J, Amanullah A. A review of nutritional factors in hypertension management. Int J Hypertens. 2013;2013:12.

73. Nowson CA, Morgan TO, Gibbons C. Decreasing dietary sodium while following a self-selected potassium-rich diet reduces blood pressure. J Nutr. 2003;133:4118-23. 